\title{
EVENT-BASED DISTRIBUTED PLANNING \& CONTROL SYSTEMS FOR PROJECT DELIVERY
}

\author{
Hyun Jeong (James) Choo, Ph.D. \\ Strategic Project Solutions, Inc. \\ jchoo@strategicprojectsolutions.net \\ Todd Zabelle \\ Strategic Project Solutions, Inc. \\ tzabelle@strategicprojectsolutions.net
}

\begin{abstract}
As modern projects become increasingly complex, dynamic, and pressed for time, delivering them on time and on budget using traditional means is becoming more and more challenging. Strategic Project Solutions, Inc. (SPS) has successfully extended Lean Manufacturing techniques to complex production-based project environments, namely large construction and industrial projects.

To support large and complex project-based production systems, such as construction, SPS has developed a webbased real-time distributed project management tool. It provides distributed cross-functional teams a means to better control workflow at the production (design, fabrication, assembly, etc.) level. This system, with named SPS Project Suite, has been implemented on several large construction projects, including London Heathrow Airport Terminal 5 Expansion (T5) and Channel Tunnel Rail Link (CTRL) Contract 105.

SPS Project Suite combines the principles of Last Planner, Lean Manufacturing, and Project Management with web technology to enable project team members to better coordinate interfaces, manage shared resources, and identify where performance improvement efforts must be invested. The use of web technology enables crossfunctional teams to work remotely. SPS Project Suite's single database contains all production-level workflow information related to a project. The single database enables resource optimization at the highest level through a real-time overview of the project's production status at any point in time.

This paper describes how SPS's web-based real-time distributed production control tool benefits projects that are large, complex and dynamic.
\end{abstract}

Keywords: Production Control, Project Management, Distributed Planning and Control, Remote and Real-Time Collaboration

\section{INTRODUCTION}

Increasing globalization and the competitive nature of free markets have combined to require organizations to continuously develop and effectively deliver new offerings to their customers. Not doing so in most industries is the kiss of death; doing so consistently enables enterprises to gain and maintain competitive advantage.

In order to develop and deliver new offerings that meet customer needs, organizations undertake projects, which require the definition, design, implementation, operation and decommissioning of temporary processes, systems and structures. . There are numerous examples of organizations that have successfully developed robust project management capabilities and realized ongoing competitive advantage, such as Toyota and its revolutionary approach to product development.

As projects have become an increasingly critical element of organizational success, academics and industry practitioners have been searching for, developing and applying alternative theories, principals, methodologies and tools designed to significantly improve project outcomes. One noteworthy development is the introduction of distributed planning and control to the project delivery process.

\section{SPS PROJECT SUITE}

Strategic Project Solutions' (SPS) production-based project management suite (SPS Project Suite) enables stakeholders involved in project-based endeavors to successfully apply distributed planning and control by effectively embedding modern management principles, including the Last Planner methodology [1,2], Lean Manufacturing techniques [4,5], and Project Management practices [3]. The SPS Project Suite, which is web-based, effectively combines real-time transparency, process improvement, and effective resource utilization. It also allows project-level integration by enabling better coordination of interfaces, improved management of shared resources, and clear identification of where performance improvement efforts should be invested. The SPS Project Suite contains all of a project's control level workflow 
information in a single database and provides a realtime status of a project's production system, thus enabling resource optimization at the highest level. Finally, the SPS Project Suite reinforces and leverages the use of cross-functional teams by forcing the changes in underlying behavior required by modern management principals.

The SPS Project Suite enables users to systematically plan and control production-level workflow and supporting material deliveries, while simultaneously facilitating learning and measuring throughout the project delivery process. In the construction industry, this translates into immediate benefits for design, engineering, fabrication, and both pre- and finalassembly phases of projects. In software development, immediate benefits are realized in the process design, architecture design, programming, testing, and rollout phases of a project.

\subsection{Last Planner Methodology}

Ballard and Howell point out that, in the traditional construction management approach, tasks to be carried out are defined prior to the start of construction and it is assumed that resources will be available when needed [2]. It is then up to production crews to gather what resources they have and to follow the schedule as best they can. This often results in a situation where the tasks cannot be performed as scheduled because actual resource availability does not match the assumed resource availability.

To alleviate this situation, Ballard and Howell proposed the Last Planner Methodology (Figure 1), which focuses on injecting reliability in planning by stabilizing workflow at the production level [2]. The main purpose of the Last Planner is to shield workers from the uncertainties they do not control through active identification of constraints (constraint analysis).

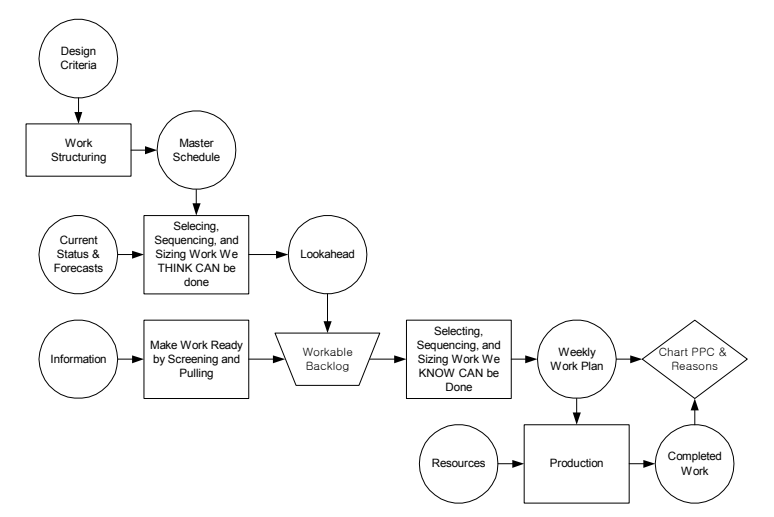

Figure 1. Last Planner Methodology

The SPS Project Suite extends Last Planner Methodology by incorporating constraint analysis into a distributed planning and control system where all project participants are responsible for performing constraint analysis. This assists project participants in identifying interfaces and predecessor/successor relationship between tasks, while achieving higher reliability due to making work ready to be performed. SPS Project Suite allows users to use different planning horizons based on type of work carried out by the production teams (e.g., daily production plans for construction teams, weekly production plans for design teams, etc).

\subsection{Lean Manufacturing Techniques}

The SPS Project Suite embodies specific Lean Manufacturing techniques [4] to align progress of production work with the supply of material, equipment, labor, and information. One of these techniques is "stopping the assembly line to immediately repair quality defects". The SPS Project Suite adopts the technique above in that it helps identify defective tasks ("constrained") early on, before resource is allocated to perform them. It also prevents defective tasks from being passed down the line (which corresponds to "stopping the assembly line"). Additionally, the project suite supports "pulling materials through the production system to meet specific customer demands." It allows the pull of required resources by streamlining the communication and coordination process for material supply and pulling material based on the status of the project's production system. It also supports "clearly documenting, updating, and constantly reporting the status of all process flows to all stakeholders involved" in that it captures tasks that are being done and not done on a real-time basis.

\subsection{Project Management Practices}

The SPS Project Suite incorporates Project Management Practices such as Work Breakdown Structure (WBS) management, scheduling, forecasting, and document control with production control.

The WBS management capability within the SPS Project Suite allows production teams to structure the work from a production perspective while maintaining alignment with the WBS hierarchy specified by the project controls (Figure 2). Thus, progress and statistics collected at the production level can be aggregated and assigned to the appropriate level within the WBS.

The SPS Project Suite also allows all project participants to view near real-time transparent project status in Gantt chart format (Figure 3). It can be configured to display the target, actual, and forecast information. The SPS Project Suite also supports document management capability by linking documents to their associated production activities. 


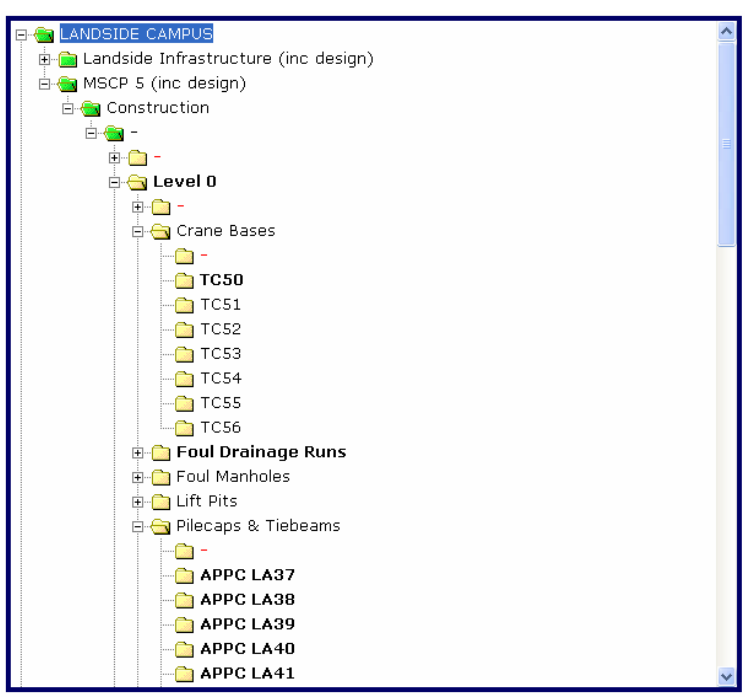

Figure 2. Work Breakdown Structure Management in SPS Project Suite

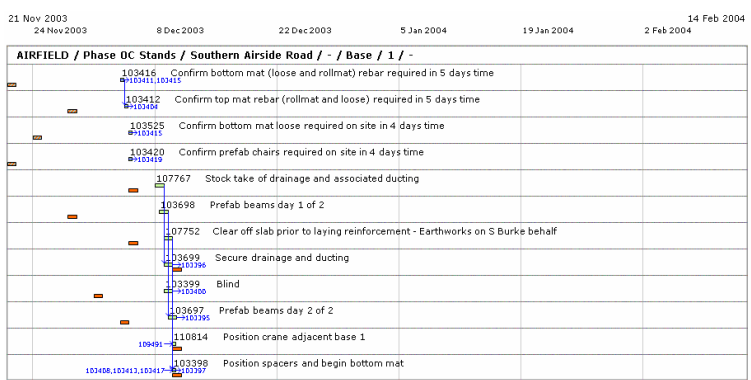

Figure 3. Gantt Chart Report from SPS Project Suite

\subsection{Functionalities}

The SPS Project Suite facilitates the co-creation of detailed weekly/daily production plans that are linked to project milestones. When tasks are not completed as planned, the SPS Project Suite mandates the entering of reasons for non-completion, which enables learning and continuous improvement that leads to improved planning reliability and project performance (Figure 4).

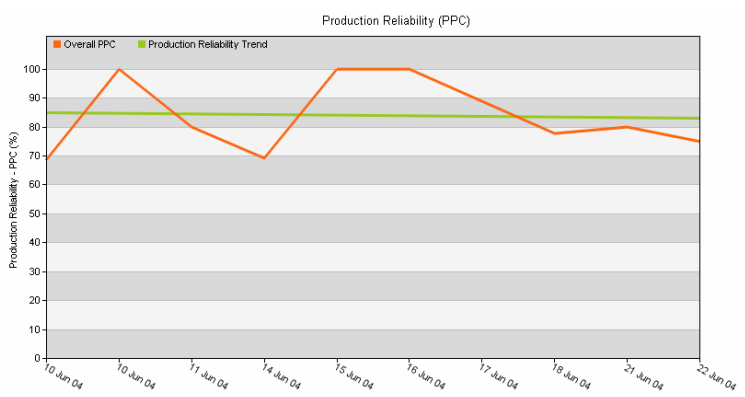

Figure 4. Production Reliability in SPS Project Suite

The SPS Project Suite also allows project related data to be attached to either a single task or a set of tasks. A common example of this functionality in construction is attaching 3D/4D product models to either a task or set of tasks. The simultaneous visualization of product and process facilitates a concurrent engineering approach, which significantly improves the efficiency and effectiveness of the project delivery process. It also allows all users to have complete transparency of whether the project and project teams are on schedule by measuring the progress against their own schedule rather than one created by a central planner, and identifies schedule variation of the production-level, which is where it can and should initially be detected and addressed.

\section{APPLICATION}

The latest production version of this system has been implemented on several large construction projects under several names (e.g., ProjectFlow, ToolFlow, SPSFlow). Some on-going projects include London's Heathrow Airport Terminal 5 Expansion (T5) [http://www.baa.com/main/airports/heathrow/termina 1_5 frame.html] and the Channel Tunnel Rail Link (CTRL) Contract 105, [http://www.ctrl.co.uk/] where it is helping the production teams achieve outstanding results.

T5, like many large, complex and dynamic projects, faces serious logistics challenges. Although there are large number of simultaneous construction activities (more than 100 trucks/hour will be entering and leaving the site through a single gate, and more than 500 construction crews will be working simultaneously on over 80 subprojects), the lay-down and staging area on-site and off-site can only accommodate approximately one day's worth of material. This problem is exacerbated by the single point of access to site, local policies on delivery times, as well as congestion around the airport.

To minimize the effect of such constraints, the SPS Project Suite is currently being used at T5 to pull material to the workface from the suppliers on a daily basis according to daily production plans, which reflect in real-time the status of the project's production system. Transparency of the site daily progress allows suppliers to monitor usage of their material on site and release deliveries accordingly. Likewise, transparency of the supplier's progress allows site to track expected material delivery time and plan accordingly.

SPS has also been working with site teams on all involved projects to increase planning reliability so that the information given to suppliers is accurate and less likely to change on a daily basis. At the same time, SPS is involved with suppliers in an effort to reduce their lead time and increase supply reliability.

\section{CONCLUSION}

A web-based real-time project management tool that enables distributed planning and control (the SPS Project Suite) encapsulates a new way to manage projects has been developed and successfully 
implemented on several complex and dynamic projects. It integrates project and production management, guiding the production teams to execute work that progresses the project based on the right sequence and timing. The collected reasons for plan failure also allow teams to continuously improve by working on the root cause of the failures.

\section{REFERENCES}

[1] Ballard, H.G. (2000). Last Planner System of Production Control. Ph.D. Dissertation, School of Civil Engineering, The University of Birmingham, UK, May, 192 pp.

[2] Ballard, G. and Howell, G. (1994). "Implementing Lean Construction: Stabilizing Work Flow." Proc. 2nd Ann. Conf. Intl. Group for Lean Constr. (IGLC-2), Pontificia Univ. Catolica de Chile, Santiago, Sept., reprinted in Alarcon (1997).

[3] PMI (1996). A Guide to the Project Management Body of Knowledge, Project Management Institute, Upper Darby, PA, USA, 176 pp.

[4] Womack, J.P. and Jones, D.T. (1996). Lean Thinking: Banish Waste and Create Wealth in Your Corporation. Simon \& Schuster, New York, NY, 350 pp.

[5] Womack, J., Jones, D., and Roos, D. (1990). The Machine that Changed the World. Rawson Associates, New York, NY, 323 pp. 